\title{
The first true obligately syntrophic propionate- oxidizing bacterium, Pelotomaculum schinkii sp. nov., co-cultured with Methanospirillum hungatei, and emended description of the genus Pelotomaculum
}

Correspondence

Frank de Bok

Frank.deBok@wur.nl

\author{
Frank A. M. de Bok, ${ }^{1}$ Hermie J. M. Harmsen, ${ }^{2}$ Caroline M. Plugge, ${ }^{1}$ \\ Maaike C. de Vries, ${ }^{1}$ Antoon D. L. Akkermans, ${ }^{1}$ Willem M. de Vos ${ }^{1}$ \\ and Alfons J. M. Stams ${ }^{1}$
${ }^{1}$ Laboratory of Microbiology, Wageningen University, Hesselink van Suchtelenweg 4, 6703 CT Wageningen, The Netherlands \\ ${ }^{2}$ Department of Medical Microbiology, University Medical Center Groningen, Hanzeplein 1, \\ 9713 GZ Groningen, The Netherlands
}

\begin{abstract}
A Gram-positive, spore-forming, syntrophic propionate-oxidizing bacterium, Pelotomaculum schinkii sp. nov. strain $\mathrm{HH}^{\top}$, was isolated as a co-culture with Methanospirillum hungatei $\mathrm{JF}-1^{\top}$ from anaerobic, freeze-dried granular sludge obtained from an upflow anaerobic sludge bed reactor treating sugar beet wastewater. The bacterium converted propionate to acetate in co-culture with Methanospirillum hungatei $\mathrm{JF}-1^{\top}$ or Methanobacterium formicicum $\mathrm{MF}^{\mathrm{NT}}$, but not in co-culture with Methanobrevibacter arboriphilus AZ. The organism could not be cultured axenically with any of the substrates tested and therefore can be considered as a (the first) true anaerobic syntrophic bacterium. The bacterium contained two distinct $16 \mathrm{~S}$ rRNA gene sequences, with $96.8 \%$ sequence similarity, which were both expressed during syntrophic growth on propionate as revealed by fluorescent in situ hybridization. The most closely related organisms are Cryptanaerobacter phenolicus LR7. ${ }^{\top}$, a bacterium that transforms phenol into benzoate, and Pelotomaculum thermopropionicum $\mathrm{SI}^{\top}$, a thermophilic, syntrophic propionate-oxidizing bacterium. Other related species belong to the Gram-positive, sulfate-reducing genus Desulfotomaculum. The type strain of Pelotomaculum schinkii is strain $\mathrm{HH}^{\top}\left(=\right.$ ATCC BAA $-615^{\top}=$ DSM $15200^{\top}$ ).
\end{abstract}

In methanogenic habitats, complex organic matter is degraded completely to $\mathrm{CO}_{2}$ and $\mathrm{CH}_{4}$ (Bryant, 1976). Propionate oxidation is an important step in this process, which requires obligately syntrophic consortia of acetogenic bacteria and methanogenic archaea. The methanogens make propionate oxidation energetically feasible by keeping the concentrations of the products $\mathrm{H}_{2}$ and formate extremely low (de Bok et al., 2004; Schink, 1997; Schink \& Stams, 2002). Most of the syntrophic propionate-oxidizing bacteria isolated so far belong to the Syntrophobacter cluster within the 'Deltaproteobacteria'. Syntrophobacter species are able to use sulfate as the electron acceptor for propionate oxidation

Published online ahead of print on 29 April 2005 as DOI 10.1099/ ijs.0.02880-0.

Abbreviation: FISH, fluorescent in situ hybridization.

The GenBank/EMBL/DDBJ accession numbers for the 'spore A' and 'spore $\mathrm{B}^{\prime} 16 \mathrm{~S}$ rRNA gene sequences of strain $\mathrm{HH}^{\top}$ are respectively X91169 and X91170.
(Harmsen et al., 1993; Wallrabenstein et al., 1995). In addition, they can grow by fermentation of pyruvate and fumarate. Smithella propionica $\mathrm{LYP}^{\mathrm{T}}$, which was isolated more recently, is phylogenetically related to the genus Syntrophus (Liu et al., 1999). This Gram-negative propionate-oxidizer lacks the ability to reduce sulfate and uses a different pathway to oxidize propionate from that used by Syntrophobacter strains. However, Smithella propionica $\mathrm{LYP}^{\mathrm{T}}$ is able to grow axenically on crotonate (de Bok et al., 2001; Liu et al., 1999). Syntrophic propionate oxidation is not restricted to Gram-negative bacteria. Wu et al. (1992) described a Gram-positive, syntrophic propionateoxidizing bacterium that is able to produce spores. Apart from its grouping within the Gram-positive bacteria, no further physiological characterization was reported. Two thermophilic, Gram-positive, syntrophic propionateoxidizing bacteria have been described, Desulfotomaculum thermobenzoicum subsp. thermosyntrophicum $\mathrm{TPO}^{\mathrm{T}}$, which grows axenically on several substrates and, like Syntrophobacter strains, can use sulfate as an electron acceptor 
(Plugge et al., 2002), and Pelotomaculum thermopropionicum $\mathrm{SI}^{\mathrm{T}}$, which lacks the ability to reduce sulfate but ferments pyruvate and fumarate in pure culture (Imachi et al., 2000, 2002). In this study, we describe a mesophilic, sporeforming, syntrophic propionate-oxidizing bacterium, strain $\mathrm{HH}^{\mathrm{T}}$, which is also closely related to Pelotomaculum thermopropionicum $\mathrm{SI}^{\mathrm{T}}$ and the genus Desulfotomaculum. This strain was obtained as a defined co-culture with Methanospirillum hungatei $\mathrm{JF}^{-1}{ }^{\mathrm{T}}$ and could not grow axenically on any of the substrates tested.

Methanospirillum hungatei JF- ${ }^{\mathrm{T}} \quad\left(=\mathrm{DSM} \quad 864^{\mathrm{T}}\right)$, Methanobacterium formicicum $\mathrm{MF}^{\mathrm{NT}}$ (=DSM $1535^{\mathrm{NT}}$ ) and Methanobrevibacter arboriphilus AZ (=DSM 744) were obtained from the Deutsche Sammlung von Mikroorganismen und Zellkulturen (Braunschweig, Germany). A bicarbonate-buffered mineral medium was used, with the following composition: $3 \mathrm{mM} \mathrm{Na}_{2} \mathrm{HPO}_{4}, 3 \mathrm{mM} \mathrm{KH}_{2} \mathrm{PO}_{4}$, $5.6 \mathrm{mM} \mathrm{NH}_{4} \mathrm{Cl}, 0.75 \mathrm{mM} \mathrm{CaCl}_{2}, 0.5 \mathrm{mM} \mathrm{MgCl}_{2}, 5 \mathrm{mM}$ $\mathrm{NaCl}, 50 \mathrm{mM} \mathrm{NaHCO}, 1 \mathrm{mM} \mathrm{Na}_{2} \mathrm{~S}, 7 \cdot 5 \mu \mathrm{M} \mathrm{FeCl}_{2}, 1 \mu \mathrm{M}$ $\mathrm{H}_{3} \mathrm{BO}_{3}, 0.5 \mu \mathrm{M} \mathrm{ZnCl}, 0 \cdot 1 \mu \mathrm{M} \mathrm{CuCl}_{2}, 0.5 \mu \mathrm{M} \mathrm{MnCl}_{2}$, $0 \cdot 5 \mu \mathrm{M} \mathrm{CoCl}, 0 \cdot 1 \mu \mathrm{M} \mathrm{NiCl}, 0 \cdot 1 \mu \mathrm{M} \mathrm{Na}_{2} \mathrm{SeO}_{3}, 0 \cdot 1 \mu \mathrm{M}$ $\mathrm{Na}_{2} \mathrm{WO}_{4}, 0 \cdot 1 \mu \mathrm{M} \mathrm{Na} \mathrm{MoO}_{4}, 0 \cdot 5 \mathrm{mg}$ EDTA $l^{-1}$ and the following vitamins $\left(\mathrm{mg} \mathrm{l}^{-1}\right): 0 \cdot 02$ biotin, $0 \cdot 2$ nicotinic acid, $0 \cdot 5$ pyridoxine, $0 \cdot 1$ riboflavin, $0 \cdot 2$ thiamin, $0 \cdot 1$ cyanocobalamin, $0 \cdot 1 p$-aminobenzoic acid, $0 \cdot 1$ pantothenic acid, $0 \cdot 1$ lipoic acid and $0 \cdot 1$ folic acid. Methanogenic archaea were cultured routinely at $37^{\circ} \mathrm{C}$ in $120 \mathrm{ml}$ serum flasks with $50 \mathrm{ml}$ medium and a gas phase of $1.7 \mathrm{~atm} . \mathrm{H}_{2} / \mathrm{CO}_{2}(80: 20$, $\mathrm{v} / \mathrm{v})$. Prior to inoculation of the propionate-oxidizing bacteria, $\mathrm{CH}_{4}$ and residual $\mathrm{H}_{2}$ were removed and replaced by $1.7 \mathrm{~atm} . \mathrm{N}_{2} / \mathrm{CO}_{2}(80: 20, \mathrm{v} / \mathrm{v})$. Propionate-oxidizing bacteria were inoculated in $\mathrm{H}_{2} / \mathrm{CO}_{2}$-pregrown cultures of Methanospirillum hungatei JF- ${ }^{\mathrm{T}}$, Methanobacterium formicicum $\mathrm{MF}^{\mathrm{NT}}$ or Methanobrevibacter arboriphilus AZ. Routinely, $5 \%$ of a pasteurized $\left(20 \mathrm{~min}, 85^{\circ} \mathrm{C}\right)$ methanogenic co-culture was used as the inoculum. After addition of sodium propionate $(20 \mathrm{mM}$ final concentration), the cultures were incubated at $37^{\circ} \mathrm{C}$. Percoll density-gradient centrifugation was carried out under anoxic conditions using a glove box with $\mathrm{N}_{2} / \mathrm{H}_{2}(96: 4, \mathrm{v} / \mathrm{v})$ as the gas phase and airtight centrifuge tubes for centrifugation steps outside the glove box. Traces of oxygen were removed from the glove box by circulating the gas phase over a platinum catalyst column. Cells were collected from a 0.51 propionate-oxidizing enrichment culture by centrifugation at $16000 \mathrm{~g}$. The cell pellet was resuspended in a mixture of

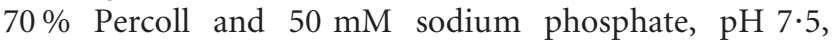
containing $2 \mathrm{mM} \mathrm{Na} \mathrm{Na}_{2} \mathrm{~S}$. The cells were separated in a Percoll gradient, which was generated in a $9 \mathrm{ml}$ centrifuge tube at $30000 \mathrm{~g}$ and $18^{\circ} \mathrm{C}$ for $30 \mathrm{~min}$.

Organic acids were measured with a Spectrasystem HPLC system equipped with an autosampler and refractometer. The acids were separated on a Polyspher OAHY column (30 $\mathrm{cm} \times 6.5 \mathrm{~mm}$; Merck) in $0.005 \mathrm{M} \mathrm{H}_{2} \mathrm{SO}_{4}$ at a flow rate of $0.6 \mathrm{ml} \mathrm{min}{ }^{-1}$ and a column temperature of $60{ }^{\circ} \mathrm{C}$. The acids eluting from the column were quantified by differential refractometry. $\mathrm{H}_{2}$ and $\mathrm{CH}_{4}$ were measured using a Packard-Becker 417 gas chromatograph equipped with a thermal conductivity detector and a molecular sieve $13 \mathrm{X}$ (60/80 mesh). The column temperature was $50^{\circ} \mathrm{C}$ and the carrier gas was argon at a flow rate of $30 \mathrm{ml} \mathrm{min}^{-1}$. To determine whether strain $\mathrm{HH}^{\mathrm{T}}$ uses a randomizing pathway of propionate oxidation, a co-culture was grown in the presence of $5 \mathrm{mM} 3-{ }^{13} \mathrm{C}$-propionate (de Bok et al., 2001). At the end of the exponential growth phase, a sample was withdrawn from this culture and analysed for isotopes using ${ }^{13} \mathrm{C}-\mathrm{NMR}$ spectroscopy. A proton-decoupled ${ }^{13} \mathrm{C}-\mathrm{NMR}$ spectrum was recorded at $75 \cdot 47 \mathrm{MHz}$ on a Bruker AMX300 NMR spectrometer as described previously (de Bok et al., 2001).

Nucleic acids were isolated from $10 \mathrm{ml}$ of a lateexponential-phase enrichment culture as described previously (Harmsen et al., 1995). Bacterial 16S rRNA genes present in the enrichment culture were amplified by PCR as described by Harmsen et al. (1993) using a set of universal $16 \mathrm{~S}$ rRNA-based primers containing restriction sites (in bold) for BamHI and PstI to facilitate cloning: the forward primer (5'-CACGGATCCGGACGGGTGAGTAACACG) corresponded to Escherichia coli positions 106-124 and the reverse primer (5'-GTGCTGCAGGGTTACCTTGTTAC GACT) to E. coli positions 1493-1510. Recombinant plasmids were obtained as described previously using pUC18 as cloning vector and E. coli TG1 as host (Harmsen et al., 1996). DNA sequencing was done using the dideoxy chain-termination method (Sanger et al., 1977) adapted for cycle-sequencing with Taq polymerase as described in the Life Science Technologies (now Invitrogen) manual. All enzymes for DNA manipulations were obtained from Life Science Technologies. Unlabelled oligonucleotides were purchased from Pharmacia. Partial $16 \mathrm{~S}$ rRNA gene nucleotide sequences were aligned with those of other bacteria, taking into account sequence similarity and higher order structure, using the alignment tool of the ARB software package (Strunk \& Ludwig, 1995). Slot-blot hybridization experiments were performed on Hybond $\mathrm{N}+$ filters (GE Healthcare). Nucleic acid samples containing approximately $50 \mathrm{ng}$ DNA were applied to the membrane with a Hybridot manifold (Life Science Technologies) and immobilized according to Church \& Gilbert (1984). The membranes were pretreated with hybridization buffer $(0.5 \mathrm{M}$ sodium phosphate, $\mathrm{pH} 7 \cdot 2$, $7 \%$ SDS, $1 \%$ BSA and $1 \mathrm{mM}$ EDTA) for $30 \mathrm{~min}$ prior to hybridization with $100 \mathrm{ng}\left[\gamma_{-}{ }^{32} \mathrm{P}\right] \mathrm{ATP}$-labelled probes. All membranes were hybridized at $40{ }^{\circ} \mathrm{C}$ and washed in $1 \%$ SDS, $1 \times \operatorname{SSC}(0.15 \mathrm{M} \mathrm{NaCl}, 0.015 \mathrm{M}$ sodium citrate, $\mathrm{pH} 7 \cdot 0$ ) wash buffer at $50^{\circ} \mathrm{C}$. The membranes were exposed to a Kodak X-ray film or exposed to a phosphorimager screen. The screen was then scanned for radioactive response on a PhosphorImager (Molecular Dynamics). Digital signals were processed by the manufacturer's software (ImageQuant). Cells were prepared for fluorescent in situ hybridization (FISH) either by mixing culture samples $1: 1$ directly with $8 \%$ paraformaldehyde or by concentrating 
the culture samples by centrifugation and then resuspending the cell pellets in PBS $(130 \mathrm{mM} \mathrm{NaCl}, 10 \mathrm{mM}$ sodium phosphate, $\mathrm{pH} 7 \cdot 2$ ) containing $4 \%$ paraformaldehyde. Cells were fixed for $2 \mathrm{~h}$ and then washed with PBS and resuspended in PBS/ethanol $(1: 1)$. Alternatively, cells were fixed by mixing the culture samples $1: 1$ with ice-cold $96 \%$ ethanol or resuspending cell pellets in PBS/ethanol $(1: 1)$. Samples were stored at $-20{ }^{\circ} \mathrm{C}$. Samples were dried onto glass slides $(10 \mu \mathrm{l}$ per well), washed with Milli-Q water and then dehydrated in an increasing ethanol series $(3 \mathrm{~min}$ each in 50,80 and $96 \% \mathrm{v} / \mathrm{v}$ ethanol). To test whether lysozyme improved the permeabilization, slides were incubated in a lysozyme solution $\left(100 \mathrm{mg} \mathrm{ml}^{-1}\right)$ for $10 \mathrm{~min}$ at $50^{\circ} \mathrm{C}$. The cells were hybridized for $1.5 \mathrm{~h}$ with fluorescein- or Cy3labelled oligonucleotide probes at $50{ }^{\circ} \mathrm{C}$ and formamide at 0, 10, 20, 30, 40 and 50\%, according to Amann (1996). Fluorescent cells were detected with an Olympus $\mathrm{BH} 2$ epifluorescence microscope.

The propionate-oxidizing culture was enriched from freezedried granular sludge from a full-scale upflow anaerobic sludge bed (UASB) reactor treating sugar beet waste (CSM, Breda, The Netherlands). After freeze-drying, the sludge had been stored aerobically for more than 2 years at room temperature. Bottles with freshly prepared medium $(50 \mathrm{ml})$ were inoculated with $0.2 \mathrm{~g}$ freeze-dried granular sludge. After addition of $20 \mathrm{mM}$ sodium propionate and $10 \%(\mathrm{v} / \mathrm{v})$ of a $\mathrm{H}_{2} / \mathrm{CO}_{2}$-grown culture of Methanospirillum hungatei $\mathrm{JF}-1^{\mathrm{T}}$, the enrichment culture was incubated at $37^{\circ} \mathrm{C}$. After 3 months, the propionate was depleted and $\mathrm{CH}_{4}$ was produced. Acetate was detected in only small amounts, indicating the presence of acetoclastic methanogens. Propionate-oxidizing bacteria were further purified by repeated rounds of pasteurization for $30 \mathrm{~min}$ at $85^{\circ} \mathrm{C}$ and subculturing in the presence of Methanospirillum hungatei $\mathrm{JF}-1^{\mathrm{T}}$. The highest dilution with growth (usually dilution $10^{8}$ ) was always used for subculturing. After six transfers, the culture consisted of two morphotypes, Methanospirillum hungatei $\mathrm{JF}^{-1}{ }^{\mathrm{T}}$ and a rod-shaped bacterium, which formed endospores (Fig. 1). No other bacteria were observed microscopically. However, upon addition of glucose, a long-rod-shaped bacterium developed. This bacterium remained, even after additional rounds of pasteurization and subculturing. The doubling time of the culture was approximately 7 days and the culture had a lag phase varying from 1 to 8 weeks.

To isolate strain $\mathrm{HH}^{\mathrm{T}}$ as a defined co-culture with Methanospirillum hungatei $\mathrm{JF}-1^{\mathrm{T}}$, cells from a $0.5 \mathrm{l}$ propionate-oxidizing enrichment culture were separated in a Percoll gradient. Two bands were visible in the gradient, of which the upper band contained the (short) rod-shaped bacteria and the lower band Methanospirillum hungatei. Cells with the morphology of the long-rod-shaped bacteria were not detected (microscopically) in either of these bands. The upper band containing the propionate-oxidizing bacteria was collected and inoculated in freshly prepared basal medium. Four dilution series up to $10^{10}$ dilution were prepared from this culture in exponentially growing Methanospirillum hungatei JF- ${ }^{\mathrm{T}}$ cultures from which $\mathrm{CH}_{4}$ and residual $\mathrm{H}_{2}$ were removed by flushing with $\mathrm{N}_{2} / \mathrm{CO}_{2}$. In two of the four dilution series, yeast extract $\left(1 \mathrm{~g} \mathrm{l}^{-1}\right)$ and casein tryptic peptones $\left(1 \mathrm{~g} \mathrm{l}^{-1}\right)$ were added to stimulate growth. Sodium propionate $(20 \mathrm{mM})$ was added to each of the cultures and all bottles were incubated at $37^{\circ} \mathrm{C}$ in the dark. In the dilution series containing yeast extract and peptones, $\mathrm{CH}_{4}$ was produced up to the $10^{9}$ dilution within 6 weeks. At this time-point, $\mathrm{CH}_{4}$ was detected only in the $10^{1}$ dilution of the series that did not contain yeast extract and peptones. However, after 4 months, $\mathrm{CH}_{4}$ was produced up to the $10^{9}$ dilution in the series without yeast extract and peptones. Purity of this culture was checked by inoculating batches in medium with glucose $(10 \mathrm{mM})$, pyruvate $(20 \mathrm{mM})$, yeast extract $\left(1 \mathrm{~g} \mathrm{l}^{-1}\right)$ or casein tryptic peptones $\left(1 \mathrm{~g} \mathrm{l}^{-1}\right)$. Growth was not observed in any of these cultures, indicating that the culture consisted of the spore-forming, propionate-oxidizing bacterium and Methanospirillum hungatei JF- ${ }^{\mathrm{T}}$ only (Fig. 1). The propionate-oxidizing bacteria were $1 \times 2 \cdot 0-2 \cdot 5 \mu \mathrm{m}$ in size; non-motile and produced centrally located endospores in the late exponential phase. Sequence analysis of the $16 \mathrm{~S}$ rRNA genes amplified from this culture revealed that both sequences obtained from the enrichment culture were still present in equal amounts in this culture.

An enrichment culture that had been pasteurized and subcultured at least 15 times under syntrophic conditions was used for phylogenetic analysis. PCR amplification of the 16S rRNA genes from nucleic acids isolated from this culture resulted in a product of the expected size of $1.4 \mathrm{~kb}$. This fragment was digested with BamHI and PstI and ligated in pUC18 linearized with the same enzymes. The ligation products were transformed into E. coli TG1 cells, which resulted in 38 recombinant plasmids. Ten of the recombinant plasmids were characterized by sequence analysis of the insert DNA using the universal 16S rRNA primer 1115 (E. coli positions 1100-1115; Lane, 1991). Four of these plasmids contained inserts with identical sequences of the V6 region of the $16 \mathrm{~S}$ rRNA, indicated as 'spore A' sequences. Five other plasmids also contained identical sequences, indicated as 'spore B'. One plasmid contained an unidentified sequence. Two plasmids containing a spore A or B $16 \mathrm{~S}$ rRNA gene sequence were selected for further analysis and their inserts were sequenced completely, resulting in sequences of 1361 and 1362 bp, respectively. These sequences have been deposited in the EMBL database with accession numbers X91169 (spore A) and X91170 (spore B). The similarity between the two $16 \mathrm{~S}$ rRNA gene sequences was $96 \cdot 8 \%$. Specific oligonucleotide probes were designed against the V6 region of the type A and type B 16S rRNA gene sequences (5'-GGACTACTGACACCTTTGTGTCTC and 5'-GAGACTGTCGGATACTTTCATCC for A and B, respectively). A slot blot containing approximately $100 \mathrm{ng}$ of each of the 38 plasmids was hybridized with both probes to determine the ratio in which the clone library represented the two sequence types. In addition, a comparable amount 

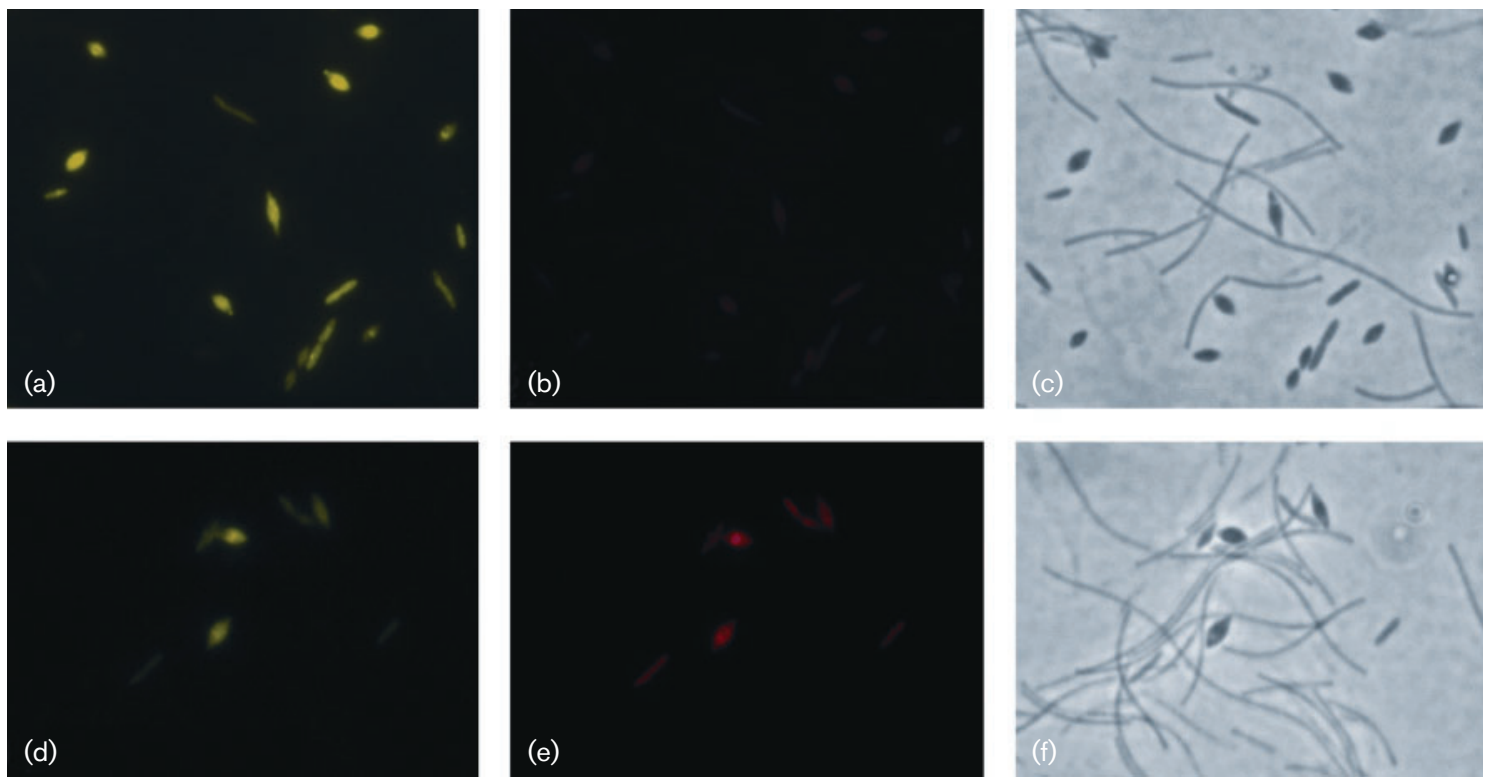

Fig. 1. In situ hybridization of the spore-forming, syntrophic propionate-oxidizing culture. (a) Cells probed with the fluorescein-labelled universal probe Eub338. (b) Background fluorescence through a Сy3 filter in the same field as (a) without Cy3 probe. (d)-(e) Cells probed with fluorescein-labelled spore A-specific probe SPA177 (d) and the Cy3-labelled spore Bspecific probe SPB177 (e). Corresponding phase-contrast micrographs are shown in (c) and (f). The long, thin, curved rods are Methanospirillum hungatei $\mathrm{JF}-1^{\top}$; all other cells belong to strain $\mathrm{HH}^{\top}$.

of DNA obtained from five different PCR amplifications was added to the blot to determine whether selective cloning had occurred. Thirteen of the 38 plasmids gave a positive signal with the type A-specific probe and 17 plasmids gave a positive signal with the type B-specific probe. All five PCR products hybridized with both probes with approximately the same efficiency, indicating that the two 16S rRNA gene sequences were present in equal amounts after amplification.

Sequence heterogeneities in the rRNA operons are not an unusual property of bacteria, as this has also been described for other Gram-positive bacteria such as Paenibacillus polymyxa (Nubel et al., 1996), Bifidobacterium adolescentis (Satokari et al., 2001) and Clostridium perfringens (Shimizu et al., 2001). However, to exclude the possibility that there were two closely related bacterial species left in the coculture, FISH was used to target both sequences in individual cells. Based on sequence differences observed in the V2 regions of the 16S rRNA gene sequences (Table 1), two fluorescently labelled oligonucleotide probes were designed to determine whether the type $\mathrm{A}$ and type $\mathrm{B}$ sequences belonged to a single organism. The best hybridization results were obtained with early exponential-phase cells that were fixed with paraformaldehyde and hybridized in the presence of $10 \%$ formamide. Both V2 probes were detected in the same cells and none of the cells hybridized with only one of these probes, although faint signals were detected in some cells (Fig. 1). To exclude crosshybridization with non-target bacteria, three environmental strains, Succiniclasticum ruminis DSM $9236^{\mathrm{T}}$, Sporomusa paucivorans DSM $3697^{\mathrm{T}}$ and Clostridium sporosphaeroides DSM $1294^{\mathrm{T}}$, and five clinical strains (identified as Eubacterium cylindroides, Clostridium butyricum, Clostridium nexile, Fusobacterium mortiferum and Clostridium cadaveris) were fixed and hybridized with both V2 probes under the conditions which were optimal for strain $\mathrm{HH}^{\mathrm{T}}$, but a signal was detected for none of these strains. Based on these results, we conclude that strain $\mathrm{HH}^{\mathrm{T}}$ contains two different $16 \mathrm{~S}$ rRNA gene sequences which are both expressed during syntrophic growth on propionate.

The propionate-oxidizing bacterium strain $\mathrm{HH}^{\mathrm{T}}$ oxidized propionate to acetate and $\mathrm{CH}_{4}$ with either Methanospirillum hungatei $\mathrm{JF}^{-1}{ }^{\mathrm{T}}$ or Methanobacterium formicicum $\mathrm{MF}^{\mathrm{NT}}$, but not with Methanobrevibacter arboriphilus AZ, which does not utilize formate as a substrate. The organism did not grow at higher temperatures $\left(45-65^{\circ} \mathrm{C}\right)$ with

Table 1. Bacterial oligonucleotide probe Eub338 and specific probes directed against the type $A$ and type $B 16 S$ rRNA sequences of strain $\mathrm{HH}^{\top}$

\begin{tabular}{|lcc|}
\hline Probe & Label & Sequence $\left(\mathbf{5}^{\prime} \mathbf{-} \mathbf{3}^{\prime}\right)$ \\
\hline Eub338 & Fluorescein & GCTGCCTCCCGTAGGAGT \\
SPA177 & Fluorescein & TGTTCCCTTGAGCGTATC \\
SPB177 & Cy3 & GTTTTCCGTGAGCGTATC \\
\hline
\end{tabular}


Methanothermobacter thermautotrophicus strains $\Delta \mathrm{H}^{\mathrm{T}}$ and Z245. The syntrophic culture converted $1 \mathrm{~mol}$ propionate to about $0.9 \mathrm{~mol}$ acetate and $0.7 \mathrm{~mol} \mathrm{CH}_{4}$. The growth rate of strain $\mathrm{HH}^{\mathrm{T}}$ depended strongly on the number of methanogens present. During enrichment, only $10 \%(\mathrm{v} / \mathrm{v})$ of a $\mathrm{H}_{2} / \mathrm{CO}_{2}$-grown culture of Methanospirillum hungatei JF- $1^{\mathrm{T}}$ was added, and the maximum doubling time observed in these cultures was only approximately 7 days. For further isolation procedures, the culture was inoculated into batches in which Methanospirillum hungatei $\mathrm{JF}-1^{\mathrm{T}}$ was pregrown on $\mathrm{H}_{2} / \mathrm{CO}_{2}$. In these batches, the doubling time was close to 3 days, most likely as a result of the high density of Methanospirillum hungatei JF- $1^{\mathrm{T}}$. The time needed for a $10^{9}$-diluted culture to show visible growth suggests that the doubling time is even shorter under optimal conditions, approximately 1.5 days. Yeast extract $\left(1 \mathrm{~g} \mathrm{l}^{-1}\right)$ and fumarate stimulated growth, but the culture was not able to grow on these compounds in the absence of propionate and Methanospirillum hungatei $\mathrm{JF}-1^{\mathrm{T}}$. When fumarate $(20 \mathrm{mM})$ was added, propionate was degraded more rapidly and, in addition to acetate, malate and succinate were produced. Addition of fumarate did not affect the biomass yield, which was determined by measuring the optical density. Other substrates which were tested for syntrophic growth (at $20 \mathrm{mM}$ unless indicated), but which were not utilized, included lactate, pyruvate, fumarate, malate, succinate, acetate, citrate, $\alpha$-ketoglutarate, butyrate, 3 -hydroxybutyrate, 4-hydroxybutyrate, isobutyrate, crotonate, benzoate, glucose, fructose, xylose, methanol, ethanol, isopropanol, propanol, glycerol, butanediol, glycine, aspartate, serine, alanine, glutamate and proline $(5 \mathrm{mM})$. The electron acceptors sulfate, thiosulfate, sulfite, nitrate, chlorate, iron(III) EDTA, fumarate, proline, glycine, crotonate, anthraquinone disulfonate $(2.5 \mathrm{mM})$ and elemental sulfur $\left(4 \mathrm{~g} \mathrm{l}^{-1}\right)$ did not support axenic growth of pasteurized cultures in the presence of propionate. Pasteurized cultures did not grow on $\mathrm{H}_{2} / \mathrm{CO}_{2}$, formate or pyruvate.

Most syntrophic propionate-oxidizing bacteria use the randomizing methylmalonyl CoA pathway to oxidize propionate (Houwen et al., 1990, 1991; Plugge et al., 1993). An alternative pathway, which has recently been proposed for Smithella propionica $\mathrm{LYP}^{\mathrm{T}}$, explains the presence of a non-randomizing pathway in methanogenic ecosystems and enrichment cultures (de Bok et al., 2001). A ${ }^{13} \mathrm{C}$-NMR experiment with strain $\mathrm{HH}^{\mathrm{T}}$ grown on $3{ }^{13} \mathrm{C}$ propionate yielded both 1 - and $2-{ }^{13} \mathrm{C}$-acetate, indicating that the organism uses the methylmalonyl CoA pathway (data not shown). The presence of this pathway has also been demonstrated in the closely related Desulfotomaculum thermobenzoicum subsp. thermosyntrophicum $\mathrm{TPO}^{\mathrm{T}}$ (Plugge et al., 2002) by measuring some of the key enzymes of the pathway. We tested strain $\mathrm{HH}^{\mathrm{T}}$ for axenic growth on several intermediates of this pathway, including several combinations with propionate, but growth was not observed in any of these cultures. As indicated above, fumarate stimulated syntrophic growth on propionate in this organism, probably by preventing the energetically unfavourable oxidation of succinate to fumarate during propionate oxidation. Syntrophobacter species are able to ferment intermediates due to their ability to couple the energetically unfavourable oxidations to fumarate reduction. Apparently, strain $\mathrm{HH}^{\mathrm{T}}$ is not able to couple the electrons released in the three oxidation steps during propionate oxidation to fumarate reduction. Thus, strain $\mathrm{HH}^{\mathrm{T}}$ seems to represent the first true obligately syntrophic anaerobic bacterium.

Comparative sequence analysis of the 16S rRNA gene sequences derived from the enrichment culture (spore A and spore B) with other sequences revealed that strain $\mathrm{HH}^{\mathrm{T}}$ clusters phylogenetically with species of the genus Desulfotomaculum and is most closely related to Pelotomaculum strain FP, an organism for which two sequences ( $r r n A$ and $r r n B$ ) have also been deposited in GenBank (accession numbers $\mathrm{AB} 159557$ and $\mathrm{AB} 159558$; similarity values of $98.6 \%$ for the type A sequence and the $r r n A$ sequence and $99.8 \%$ for the type B sequence and the $r r n B$ sequence). This organism is also a mesophilic, spore-forming, syntrophic propionate-oxidizing bacterium $(\mathrm{H}$. Imachi, personal communication). The closest relative which has been studied in more detail is Cryptanaerobacter phenolicus LR7. $2^{\mathrm{T}}$ ( 95.6 and $96.7 \%$ sequence similarity to the type A and type $\mathrm{B}$ sequences, respectively), an anaerobic bacterium that transforms phenol and 4-hydroxybenzoate into benzoate (Juteau et al., 2005). This organism was not tested for syntrophic growth on propionate or other compounds. Another related bacterium, the thermophilic propionate-oxidizer Pelotomaculum thermopropionicum $\mathrm{SI}^{\mathrm{T}}$, does grow syntrophically on propionate and is also unable to reduce sulfate (Imachi et al., 2002). Within the genus Desulfotomaculum, another thermophilic, sporeforming, syntrophic propionate-oxidizing bacterium $\left(\right.$ strain $\mathrm{TPO}^{\mathrm{T}}$ ) was also described recently (Plugge et al., 2002). Unlike these two thermophilic strains, we were not able to grow strain $\mathrm{HH}^{\mathrm{T}}$ axenically, despite testing all substrates that supported growth of other syntrophs. Wu et al. (1992) described a mesophilic, spore-forming, propionate-oxidizing bacterium. This strain (strain PT) was isolated in co-culture with Methanobacterium formicicum $\mathrm{MF}^{\mathrm{NT}}$ and was one of the prevalent syntrophic propionate oxidizers in the UASB granules they studied. Although somewhat shorter in length, cells of strain PT had the same characteristics as the bacterium described here; the strain produced endospores and was not able to reduce sulfate in the presence of propionate ( $\mathrm{Wu}$ et al., 1992). Besides butyrate, strain PT was not tested for growth on other substrates and, unfortunately, no phylogenetic information is available for this organism. Using stable isotope probing, it was demonstrated that, in addition to Syntrophobacter spp. and Smithella spp., Pelotomaculum spp. are important in propionate oxidation in anoxic paddy soil (Lueders et al., 2004).

Based on its physiological properties and 16S rRNA gene sequence similarity to Pelotomaculum thermopropionicum $\mathrm{SI}^{\mathrm{T}}$, we propose that strain $\mathrm{HH}^{\mathrm{T}}$ represents a novel species in 


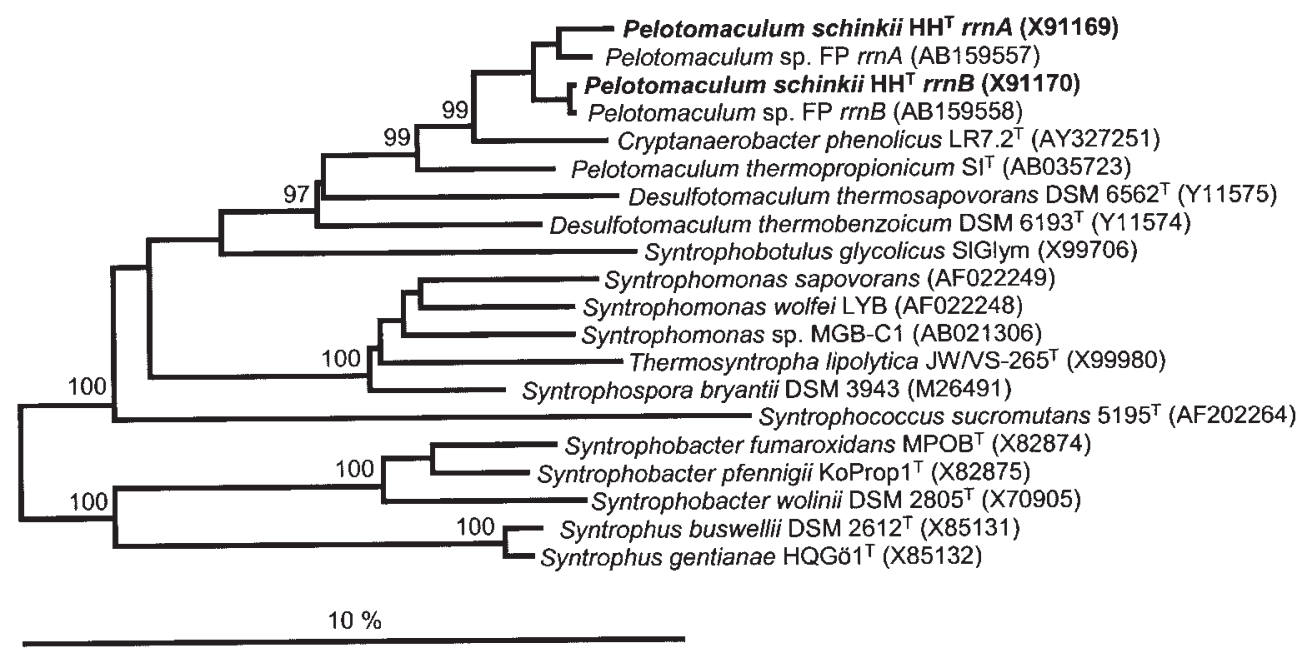

Fig. 2. Phylogenetic tree showing the relationships of the two $r$ rn sequences of Pelotomaculum schinkii sp. nov. $\mathrm{HH}^{\top}$ with published sequences. The published sequences are from the most closely related species of described bacteria and other Gram-positive and Gram-negative syntrophic bacteria. The tree is a neighbour-joining tree of a distance matrix including 1276 nucleotides between E. coli positions 125 and 1491. Bootstrap percentages, based on 1000 replications, at nodes display the significance of these nodes; only values above $95 \%$ are given. Bar, $10 \%$ sequence divergence.

the genus Pelotomaculum, Pelotomaculum schinkii sp. nov. A consensus tree based on distance-matrix and parsimony analysis is depicted in Fig. 2.

\section{Emended description of the genus Pelotomaculum Imachi et al. 2002}

Pelotomaculum (Pe.lo.to.ma'cu.lum. Gr. adj. pelos darkcoloured, hence anaerobic mud; L. neut. n. tomaculum sausage; N.L. neut. n. Pelotomaculum sausage-shaped bacteria living in anaerobic environments).

Unlike Pelotomaculum thermopropionicum, Pelotomaculum schinkii is mesophilic and converts only propionate in syntrophic association with hydrogenotrophic methanogens. All other characteristics of the genus as described by Imachi et al. (2002) remain unaffected.

\section{Description of Pelotomaculum schinkii sp. nov.}

Pelotomaculum schinkii (schin'ki.i. N.L. gen. n. schinkii named after Bernhard Schink, who studied several syntrophic conversions. The first spore-forming syntrophic bacterium, Syntrophospora bryantii, was isolated by his group).

Gram-positive rods, $1 \times 2-2 \cdot 5 \mu \mathrm{m}$ in size, which produce spherical endospores in the late exponential phase; nonmotile, strictly anaerobic. Grows syntrophically on propionate with methanogens that utilize both hydrogen and formate, such as Methanospirillum hungatei $\mathrm{JF}^{\mathrm{T}} \mathrm{T}^{\mathrm{T}}$ and Methanobacterium formicicum $\mathrm{MF}^{\mathrm{NT}}$. No organic supplements are required for growth, but yeast extract $(0 \cdot 1 \%)$ and fumarate (10-20 mM) enhance growth. Habitat: anaerobic mesophilic granular sludge.
The type strain, $\mathrm{HH}^{\mathrm{T}}\left(=\right.$ ATCC BAA $\left.-615^{\mathrm{T}}=\mathrm{DSM} 15200^{\mathrm{T}}\right)$, was isolated from freeze-dried granular sludge from a UASB reactor treating sugar beet waste in co-culture with Methanospirillum hungatei $\mathrm{JF}-1^{\mathrm{T}}$.

\section{Acknowledgements}

The authors would like to acknowledge Kees Roest and Ann-Charlotte Toes for DGGE analysis, Mahmut Altinbas and Alcina Pereira for assistance with fluorescent in situ hybridization and Hiroyuki Imachi for valuable discussions.

\section{References}

Amann, R. I. (1996). In situ identification of micro-organisms by whole cell hybridization with rRNA-targeted nucleic acid probes. In Molecular Microbial Ecology Manual, pp. 3.3.6.1-3.3.6.15. Edited by A. D. L. Akkermans, J. D. van Elsas \& F. J. de Bruijn. Dordrecht: Kluwer Academic.

Bryant, M. P. (1976). The microbiology of anaerobic digestion and methanogenesis with special reference to sewage. In Microbial Energy Conversion, pp. 107-118. Edited by H. G. Schlegel \& J. Barnes. Göttingen: E. Goltze K.G.

Church, G. M. \& Gilbert, W. (1984). Genomic sequencing. Proc Natl Acad Sci U S A 81, 1991-1995.

de Bok, F. A. M., Stams, A. J. M., Dijkema, C. \& Boone, D. R. (2001). Pathway of propionate oxidation by a syntrophic culture of Smithella propionica and Methanospirillum hungatei. Appl Environ Microbiol 67, 1800-1804.

de Bok, F. A. M., Plugge, C. M. \& Stams, A. J. M. (2004). Interspecies electron transfer in methanogenic propionate degrading consortia. Water Res 38, 1368-1375.

Harmsen, H. J. M., Wullings, B., Akkermans, A. D. L., Ludwig, W. \& Stams, A. J. M. (1993). Phylogenetic analysis of Syntrophobacter 
wolinii reveals a relationship with sulfate-reducing bacteria. Arch Microbiol 160, 238-240.

Harmsen, H. J. M., Kengen, K. M. P., Akkermans, A. D. L. \& Stams, A. J. M. (1995). Phylogenetic analysis of two syntrophic propionateoxidizing bacteria in enrichment cultures. Syst Appl Microbiol 18, 67-73.

Harmsen, H. J. M., Kengen, H. M. P., Akkermans, A. D. L., Stams, A. J. M. \& de Vos, W. M. (1996). Detection and localization of syntrophic propionate-oxidizing bacteria in granular sludge by in situ hybridization using $16 \mathrm{~S}$ rRNA-based oligonucleotide probes. Appl Environ Microbiol 62, 1656-1663.

Houwen, F. P., Plokker, J., Stams, A. J. M. \& Zehnder, A. J. B. (1990). Enzymatic evidence for involvement of the methylmalonyl-CoA pathway in propionate oxidation by Syntrophobacter wolinii. Arch Microbiol 155, 52-55.

Houwen, F. P., Dijkema, C., Stams, A. J. M. \& Zehnder, A. J. B. (1991). Propionate metabolism in anaerobic bacteria; determination of carboxylation reactions with ${ }^{13} \mathrm{C}-\mathrm{NMR}$ spectroscopy. Biochim Biophys Acta 1056, 126-132.

Imachi, H., Sekiguchi, Y., Kamagata, Y., Ohashi, A. \& Harada, H. (2000). Cultivation and in situ detection of a thermophilic bacterium capable of oxidizing propionate in syntrophic association with hydrogenotrophic methanogens in a thermophilic methanogenic granular sludge. Appl Environ Microbiol 66, 3608-3615.

Imachi, H., Sekiguchi, Y., Kamagata, Y., Hanada, S., Ohashi, A. \& Harada, H. (2002). Pelotomaculum thermopropionicum gen. nov., sp nov., an anaerobic, thermophilic, syntrophic propionate-oxidizing bacterium. Int J Syst Evol Microbiol 52, 1729-1735.

Juteau, P., Côté, V., Duckett, M.-F., Beaudet, R., Lépine, F., Villemur, R. \& Bisaillon, J.-G. (2005). Cryptanaerobacter phenolicus gen. nov., sp. nov., anaerobe that transforms phenol into benzoate via 4-hydroxybenzoate. Int J Syst Evol Microbiol 55, 245-250.

Lane, D. J. (1991). 16S/23S rRNA sequencing. In Nucleic Acid Techniques in Bacterial Systematics, pp. 115-175. Edited by E. Stackebrandt \& M. Goodfellow. Chichester: Wiley.

Liu, Y. T., Balkwill, D. L., Aldrich, H. C., Drake, G. R. \& Boone, D. R. (1999). Characterization of the anaerobic propionate-degrading syntrophs Smithella propionica gen. nov., sp. nov. and Syntrophobacter wolinii. Int J Syst Bacteriol 49, 545-556.

Lueders, T., Pommerenke, B. \& Friedrich, M. W. (2004). Stableisotope probing of microorganisms thriving at thermodynamic limits: syntrophic propionate oxidation in flooded soil. Appl Environ Microbiol 70, 5778-5786.
Nubel, U., Engelen, B., Felske, A., Snaidr, J., Wieshuber, A., Amann, R. I., Ludwig, W. \& Backhaus, H. (1996). Sequence heterogeneities of genes encoding 16S rRNAs in Paenibacillus polymyxa detected by temperature gradient gel electrophoresis. J Bacteriol 178, 5636-5643.

Plugge, C. M., Dijkema, C. \& Stams, A. J. M. (1993). Acetyl-CoA cleavage pathway in a syntrophic propionate oxidizing bacterium growing on fumarate in the absence of methanogens. FEMS Microbiol Lett 110, 71-76.

Plugge, C. M., Balk, M. \& Stams, A. J. M. (2002). Desulfotomaculum thermobenzoicum subsp. thermosyntrophicum subsp. nov., a thermophilic, syntrophic, propionate-oxidizing, spore-forming bacterium. Int J Syst Evol Microbiol 52, 391-399.

Sanger, F., Nicklen, S. \& Coulson, A. R. (1977). DNA sequencing with chain-terminating inhibitors. Proc Natl Acad Sci U S A 74, 5463-5467.

Satokari, R. M., Vaughan, E. E., Akkermans, A. D. L., Saarela, M. \& de Vos, W. M. (2001). Bifidobacterial diversity in human feces detected by genus-specific PCR and denaturing gradient gel electrophoresis. Appl Environ Microbiol 67, 504-513.

Schink, B. (1997). Energetics of syntrophic cooperation in methanogenic degradation. Microbiol Mol Biol Rev 61, 262-280.

Schink, B. \& Stams, A. J. M. (2002). Syntrophism among prokaryotes. In The Prokaryotes. An Evolving Electronic Resource for the Microbiological Community, release 3.8. Edited by M. Dworkin, K. H. Schleifer \& E. Stackebrandt. New York: Springer.

Shimizu, T., Ohshima, S., Ohtani, K., Hoshino, K., Honjo, K., Hayashi, H. \& Shimizu, T. (2001). Sequence heterogeneity of the ten rRNA operons in Clostridium perfringens. Syst Appl Microbiol 24, 149-156.

Strunk, O. \& Ludwig, W. (1995). ARB - a software environment for sequence data. Department of Microbiology, Technical University of Munich, Munich, Germany.

Wallrabenstein, C., Hauschild, E. \& Schink, B. (1995). Syntrophobacter pfennigii sp. nov., new syntrophically propionateoxidizing anaerobe growing in pure culture with propionate and sulfate. Arch Microbiol 164, 346-352.

Wu, W.-M., Jain, M. K., De Macario, E. C., Thiele, J. H. \& Zeikus, J. G. (1992). Microbial composition and characterization of prevalent methanogens and acetogens isolated from syntrophic methanogenic granules. Appl Microbiol Biotechnol 38, 282-290. 